\title{
Ultrasonic evaluation of thelarche grading in 2-8-year-old obese girls suspected of precocious pubert
}

Ultrasonograficzna ocena thelarche u 2-8-letnich dziewcząt z otyłością i podejrzeniem przedwczesnego dojrzewania płciowego

\author{
1Zahra Sadat Hosseini, ${ }^{2}$ Kobra Shiasi Arani, ${ }^{3}$ Alireza Moraveji, ${ }^{4}$ Hamid Reza Talari
}

\author{
${ }^{1}$ Department of Radiology, Department of Radiology, Faculty of Medicine, Kashan University of Medical \\ Sciences, Kashan, Iran \\ ${ }^{2}$ Research Center of Biochemistry and Nutrition in Metabolic Disorder, Research Center of Biochemistry \\ and Nutrition in Metabolic Disorder, Kashan University of Medical Science, Kashan, Iran \\ ${ }^{3}$ Department of Community Medicine, School of Medicine, Social Determinants of Health Research Center, \\ Kashan University of Medical Sciences, Kashan, Iran \\ ${ }^{4}$ Anatomical Sciences Research Center, Anatomical Sciences Research Center, Institute for Basic Sciences, \\ Kashan University of Medical Sciences, Kashan, Iran
}

\begin{abstract}
Background: The prevalence of obesity in children is increasing. In obese children, clinical examination alone is not sufficient to differentiate lipomastia from thelarche. The aim of this study was to investigate the frequency of true thelarche in obese girls suspected of precocious puberty.

Material and methods: In a cross-sectional study, 100 obese girls between the ages of 2 and 8 years were screened. Maturity stages were determined based on the Tanner scale in the questionnaire. Breast ultrasound was performed for all cases. Other uterine and ovarian laboratory tests, including blood tests to determine plasma levels of LH, FSH, oestradiol, and bone age, were also performed. Results: In ultrasonography examination of 80 children (80\%), one breast was pubertal and in 72 people both breasts were pubertal in which ultrasonography of 78 children showed puberty of right breast and 74 children showed puberty of left breast. Twenty children showed bilateral lipomastia. In clinical examination, breasts of $18.9 \%$ children seemed lipoid, $35.8 \%$ children were seriously suspicious, and $45.3 \%$ children seemed pubescent. In pelvic ultrasound, the relationship between ovarian volume and breast ultrasound grade was significant, but uterine volume was not significantly related to breast ultrasound grade. Also, uterine volume with age at ultrasonography, bone age, birth height, left ovarian volume, right ovarian volume, right breast bud diameter, and left breast bud diameter were correlated.
\end{abstract}

Conclusions: Ultrasound can help obese or overweight children to differentiate between true thelarche and lipomastia. The study also found that most suspected children had true thelarche.

Key words:

precocious puberty, early thelarche, obesity, overweight, children, ultrasonography.

\section{Introduction}

Precocious puberty is the presence of secondary sexual characteristics before the age of 8 years in girls and before the age of 9 years in boys [1]. Precocious puberty can cause secondary sexual characteristics, aggressive behaviour, and, most importantly, it can limit the final adult height [2-5]. Peripheral precocious puberty or precocious pseudo puberty is caused by secretion of sex hormones without pituitary gonadotropin stimulation [1]. Premature thelarche is breast development in girls before 8 years of age without pubic hair growth [6]. One parameter for diagnosis of complete or true precocious puberty with accelerated progress is advancement in bone age. There is no bone age advancement in the slowly progressive form of precocious puberty, and these patients usually reach their potential height without any treatment [7]. De Vries et al. 
mentioned that there will be a normal final height in a girl with premature thelarche and without any bone age advancement and pubic hair growth. So, there is no need to treat in these cases. If precocious pseudo puberty is not treated, patients usually experience secondary central precocious puberty [8]. Obesity and puberty can increase the bone age. Many studies show the association between obesity and puberty timing [911]. Chonchaiya et al. in 2008 performed a study on 62 obese children at the age of 5-17 years (38 boys and 24 girls) and showed that there is a positive relationship between obesity grading and bone age advancement [12]. This result is in line with other studies $[9,13,14]$. However, no advanced bone age and accelerated growth is observed in the early stages of precocious puberty. In girls, development of breast bud and forming the glandular tissue in the breast can be affected by hormones and occur during puberty. Physiological changes include increased subcutaneous fat and connective tissue, the proliferation of ducts and lengthening and terminal ductal lobular unit development [15]. The Tanner scale is widely used to classify natural breast development in girls. This classification is only an outward description of breast development regardless of other factors such as ultrasonic findings. Ultrasound examination is more accurate in assessing breast development than the Tanner scale [1, 16]. Garcia et al. in 2000 described ultrasonic features of normal breast development in every stage of the Tanner scale. However, this study was only a descriptive report without any statistical analysis [7]. Calcaterra et al. showed that breast volume increases with its ultrasonic grading development. They also presented quantitative data of the developing breast using ultrasound [17]. A few studies focus on the relationship between ultrasound findings and hormonal status. Although evaluation of the breast bud diameter and breast ultrasonic grading can be useful for puberty assessment, it has limited ability for differentiation between true precocious puberty and precocious pseudo puberty [15]. The aim of this study is an evaluation of the true thelarche frequency in obese girls who are suspicious of precocious puberty. Regarding the importance of this subject, precocious puberty effects and since so far no similar study has been done we decided to do this study in order to find a more affordable method, like ultrasound, which is an available, valuable, safe, acceptable for children, and non-aggressive diagnostic method. It can also differentiate breast glandular tissue from adipose tissue, assess the pelvic organ puberty, and reduce our need for complicated biochemical diagnostic methods.

\section{Material and methods}

In a cross-sectional study, 108 obese girls with breast enlargement at the age of 2-8 years, who attended a public hospital in Iran during the years 2018-2019, were analysed. Thelarche was determined on the basis of breast secondary growth at the beginning of the girl's puberty and with 2 stiffness just below the centre of the nipple unilaterally or bilaterally.

Height, weight, body mass index (BMI), and sexual maturity rating were recorded for cases. The children's height was measured using a Harpenden Stadiometer and their weight by SECA scales. BMI was calculated by using BMI formula (weight $[\mathrm{kg}] /$ height [m] squared). Uterine and ovarian volume was calculated by this formula: length $\times$ width $\times$ thickness $\times 0.52$. we set up a questionnaire for collecting information such as age, gender, reason for seeing the doctor, age of puberty in the family, history of precocious puberty in the family, history of specific medications, history of central nervous system (CNS) problems such as accident or head injury, and history of meningitis or encephalitis. Puberty stage was determined on the basis of the Tanner scale in the questionnaire, and breast ultrasound was performed for all cases.

Other para clinical tests like determination of follicle-stimulating hormone (FSH), luteinizing hormone (LH), and oestradiol plasma level were performed. Also, determination of bone age was done; In case of thelarche confirmation or being puberty of uterine and ovarian volume. In the pelvic ultrasound investigation, the following parameters were evaluated: the length and width of the uterus, endometrial thickness, anterior-posterior diameter of the fundus, the ratio of fundus diameter to cervix, and uterine volume, and for the ovary: length, width, maximum size of the biggest ovary, and ovarian volume. Breast staging in the basis of clinical examination (Tanner scale) and ultrasound were done as below (Table I) [7].

\section{Statement of ethical committee}

All procedures performed in studies involving human participants were in accordance with the ethical standards of the institutional and national research committee and with the 1964 Helsinki declaration and its later amendments.

\section{Statistical analysis}

Data were analysed by SPSS version 16.0 software. Demographic variables were described using central tendency, and quantitative variables using dispersion and qualitative variables using frequency distribution tables. The Mann-Whitney test was used for comparison of quantitative data. The Pearson correlation coefficient was used for determination of the quantitative data correlation coefficient with normal distribution, and the Spearman correlation coefficient was used for non-normal distribution. $P<0.05$ was considered significant.

\section{Results}

In our study, 108 obese or overweight girls suspected of precocious puberty, who visited a public hospital in Iran in the period 2018-2019 were analysed. Eight girls were removed from the study because of lack of cooperation and sufficient information. Of the remaining cases, 87 girls were obese and 13 girls were overweight, with the average age of 6.97 \pm 1.09 years. Their average bone age was $7.68 \pm 1.59$ years (range $3-11$ years). The bone age was advanced in $37.9 \%$ of the girls. Also, their average body mass index standard deviation score (BMI.SDS) was $2.67 \pm 1.14$ (Table II).

In clinical examination, the breasts of $18.9 \%$ of children seemed lipoid, $35.8 \%$ were seriously suspicious, and $45.3 \%$ 
Table I. Breast ultrasound grades with detailed characteristic findings compared with clinical Tanner stages

\begin{tabular}{lll}
\hline Grade & Tanner Stage & Ultrasound Grade \\
\hline 1 & Elevation of papilla only & Prepubertal stage; ill-defined hyperechoic retroareolar tissue \\
\hline 2 & $\begin{array}{l}\text { Elevation of breast and papilla as a small } \\
\text { mound; enlargement of areola diameter }\end{array}$ & $\begin{array}{l}\text { Palpable subareolar bud before elevation; hyperechoic retroareolar } \\
\text { nodule with central star-shaped or linear hypoechoic area }\end{array}$ \\
\hline 3 & $\begin{array}{l}\text { Further enlargement of breast and areola } \\
\text { with no separation of their contours }\end{array}$ & $\begin{array}{l}\text { Obvious enlargement and elevation; extending hyperechoic } \\
\text { glandular tissue away from the retroareolar areas with central } \\
\text { spider-shaped hypoechoic region }\end{array}$ \\
\hline 4 & $\begin{array}{l}\text { Projection of areola and papilla to form } \\
\text { a secondary mound above the level of the } \\
\text { breast }\end{array}$ & $\begin{array}{l}\text { Transient areolar mounding; hyperechoic periareolar fibroglandular } \\
\text { tissue with prominent central hypoechoic nodule and sometimes } \\
\text { subcutaneous adipose tissue }\end{array}$ \\
\hline 5 & $\begin{array}{l}\text { Projection of papilla only, due to recession } \\
\text { of the areola to the general contour of the } \\
\text { breast }\end{array}$ & $\begin{array}{l}\text { Mature breast contour; hyperechoic glandular tissue with increased } \\
\text { subcutaneous fat tissue and without hypoechoic central nodule }\end{array}$ \\
\hline
\end{tabular}

seemed pubescent. In this study, breast ultrasound results were divided into 5 grades, in which grade 2 and above was considered as pubertal breast and children with lipomastia and grade 1 ultrasound was considered as non-pubertal breast.

In ultrasonography of 80 children (80\%), 58.8\% were in stage 2 and $41.3 \%$ was in stage 3 . One breast was pubertal in at least 80 people (20 children had lipomastia), and both breasts were pubertal in 72 children (Table II). The average right breast bud $(9.61 \pm 5.91)$, left breast bud $(9.19 \pm 5.91)$, uterine volume average $(1.55 \pm 1.57)$, the ratio of uterine length to cervical length $(1.13 \pm 1.58)$, right ovarian volume average (1.12 $\pm 0.81)$, left ovarian volume average (1.06 \pm 0.76$), F S H$ average (1.94 \pm 2.36$)$, LH average (0.58 \pm 0.65$)$, and oestradiol average $(20.09 \pm 24.74)$ are listed in Table 11.

There is a significant correlation between chronological age and bone age $(r=0.6, p<0.001)$, BMI.SDS ( $r$ a -0.371 , $p=0.004)$, right breast ultrasound stage $\left(r_{s}=0.253, p=0.011\right)$, left breast ultrasound stage $\left(r_{s}=0.200, p=0.046\right)$, right breast bud diameter $(r=0.303, p=0.015)$, left breast bud diameter $(r=0.264, p=0.035)$, uterine volume $(r=0.263, p=0.008)$, right ovarian volume $(r=0.215, p=0.032)$, and left ovarian volume $(r=0.320, p=0.001)$ (Table III).

Bone age also had a significant relationship with advanced bone age $(E t a=0.646, p<0.001)$, left breast bud diameter $(r=0.329, p=0.022)$, right ovarian volume $(r=0.261$, $p=0.035)$, and left ovarian volume $(r=0.284, p=0.021)$. Advanced bone age in addition to bone age also had a significant relation to right breast ultrasound stage (Cramer's $V=0.342$, $p=0.033$ )

There was a correlation between BMI.SDS and right breast ultrasound stage $\left(r_{s}=-0.226, p=0.041\right)$ and left ovarian volume $(r=-0.235, p=0.033)$. There was a significant relation between clinical examination and right breast Tanner stage (Cramer's $V=0.718, p<0.001$ ) and left breast Tanner stage
(Cramer's $V=0.335, p=0.049$ ), but none of variables were correlated with Tanner stage of the left/right breast.

Right-breast ultrasound stage showed a relationship with left-breast ultrasound stage (Kendall's tau- $b=0.787$, $p=0.001)$, right-breast bud diameter $\left(r_{s}=0.448, p<0.01\right)$, left-breast bud diameter $\left(r_{s}=0.321, \stackrel{s}{=} 0.010\right)$, right ovarian volume $\left(r_{s}=0.241, p=0.016\right)$, and left ovarian volume $\left(r_{s}=0.250, p=0.012\right)$.

Left breast ultrasound stage showed a significant relationship with the right-breast bud diameter $\left(r_{s}=0.476, p<0.001\right)$, left-breast bud diameter $\left(r_{s}=0.606, p<0.001\right)$, right ovarian volume $\left(r_{s}=0.199, p=0.047\right)$, and left ovarian volume $\left(r_{s}=0.215, p=0.032\right)$. In terms of uterine and ovarian variables there was no relationship in children with lipomastia and true thelarche $(p>0.05)$.

Right breast bud diameter in addition to chronological age and left/right breast ultrasound diameter showed a significant relationship with left-breast bud diameter $(r=0.726$, $p<0.001)$, uterine volume $(r=0.328, p=0.008)$, the ratio of uterine length to cervical length $(r=0.535, p<0.001)$, left ovarian volume $(r=0.286, p=0.022)$, and FSH level $(r=0.378$, $p=0.043)$

Left-breast bud diameter, in addition to chronological age, bone age, left/right breast ultrasound stage and right-breast bud diameter, had a significant relationship with uterine volume $(r=0.430, p<0.001)$, the ratio of uterine length to cervical length $(r=0.325, p=0.009)$, left ovarian volume $(r=0.307$, $p=0.014)$, and FSH level $(r=0.400, p=0.032)$.

Uterine volume, in addition to chronological age and right/ left-breast bud diameter, showed correlation with right ovarian volume $(r=0.446, p<0.001)$, left ovarian volume $(r=0.429$, $p<0.001$ ), and FSH level, while the ratio of uterine length to cervical length had a significant relationship only with right/leftbreast bud diameter. 
Table II. Descriptive characteristics of study cases in terms of demographic variables, clinical examination, ultrasonic, and laboratory findings

\begin{tabular}{|c|c|c|c|c|c|}
\hline Variable & & Number & Grading & $\begin{array}{l}\text { Frequency } \\
\text { (percentage) }\end{array}$ & $\begin{array}{l}\text { average } \\
\pm \text { Standard } \\
\text { deviation }\end{array}$ \\
\hline Age & & 100 & - & - & $6.97 \pm 1.09$ \\
\hline Bone age & & 66 & - & - & $7.68 \pm 1.59$ \\
\hline Advanced bone age & & 66 & - & (37.9) 25 & - \\
\hline BMI.SDS & & 82 & - & - & $2.67 \pm 1.14$ \\
\hline Clinical examination* & & 53 & $\begin{array}{l}\text { Lipoid } \\
\text { Highly } \\
\text { suspicious } \\
\text { pubertal }\end{array}$ & $\begin{array}{l}(18.9) 10 \\
(35.8) 19 \\
\\
(45.3) 24\end{array}$ & - \\
\hline Tanner stage** & Right/left breast & 80 & $\begin{array}{l}2 \\
3\end{array}$ & $\begin{array}{l}(58.8) 47 \\
(41.3) 33\end{array}$ & - \\
\hline \multirow[t]{4}{*}{ Ultrasound stage } & Right breast & 100 & $\begin{array}{l}1 \\
2 \\
3 \\
4\end{array}$ & $\begin{array}{l}(22.0) 22 \\
(73.0) 73 \\
(2.0) 2 \\
(2.0) 2\end{array}$ & - \\
\hline & Left breast & 100 & $\begin{array}{l}1 \\
2 \\
3 \\
4\end{array}$ & $\begin{array}{l}(26.0) 26 \\
(68.0) 68 \\
(3.0) 3 \\
(3.0) 3\end{array}$ & - \\
\hline & Puberty of one breast & 100 & & (80.0) 80 & - \\
\hline & $\begin{array}{l}\text { Puberty of both } \\
\text { breasts }\end{array}$ & 100 & & (72.0) 72 & - \\
\hline \multirow[t]{2}{*}{ Breast bud diameter* } & right & 64 & & - & $5.58 \pm 9.61$ \\
\hline & left & 64 & & - & $5.91 \pm 9.19$ \\
\hline \multirow[t]{2}{*}{ Uterine ultrasound } & uterine volume & 100 & & - & $1.57 \pm 1.55$ \\
\hline & $\begin{array}{l}\text { The ratio of uterine } \\
\text { length to cervical } \\
\text { length }\end{array}$ & 100 & & - & $1.58 \pm 1.13$ \\
\hline \multirow[t]{2}{*}{ Ovarian volume } & Right & 100 & & - & $0.81 \pm 1.12$ \\
\hline & left & 100 & & - & $0.76 \pm 1.06$ \\
\hline FSH & & 39 & & - & $1.94 \pm 2.36$ \\
\hline LH & & 41 & & - & $0.58 \pm 0.65$ \\
\hline Oestradiol & & 41 & & - & $20.09 \pm 24.74$ \\
\hline
\end{tabular}

*These variables were added during the study, so their number is lower.

**The number of people in this variable is lower than the number of ultrasounds due to the lack of cooperation of patients and defects in the file. 
Right ovarian volume, in addition to chronological age, bone age, right/left breast ultrasound stage, and uterine volume, also showed a relationship with left ovarian volume $(r=0.837, p<0.001)$, while left ovarian volume had a significant relationship with all variables except advanced bone age, right/left-breast Tanner volume, the ratio of uterine length to cervical length, and laboratory findings.

FSH level, in addition to right/left breast bud diameter and uterine volume, had a significant relationship with $\mathrm{LH}$ level $(r=0.691, \mathrm{p}<0.001)$. LH level showed correlation only with FSH level, and oestradiol level had no correlation with any variables (Table III).

\section{Discussion}

This study was done to evaluate the frequency of true thelarche in obese and overweight and 2-8-year-old girls who visited a public hospital in Iran in the years 2018 and 2019. Clinical examination, laboratory findings, and bone age determination have been used until now for the evaluation of precocious puberty, and ultrasound has not played a significant role. While ultrasound can differentiate adipose tissue and breast glandular tissue, it can also play an important role in examining pelvic organ maturity. In this study, we tried to show how ultrasound is useful along with clinical examination, pelvic organ ultrasound, and other methods.

One of the important results of our study is the high frequency of true thelarche in obese children, so that $80 \%$ of the children had thelarche at least in 1 breast and $72 \%$ in 2 breasts. Therefore, we can say that if an obese girl in precocious puberty age has prominent breasts, it is $80 \%$ likely that she has thelarche unilaterally or bilaterally.

The younger the age, the more important it is to diagnose precocious puberty. If precocious puberty begins before 6 years old, it is usually progressive, effects final height, and should be treated. In our study, there was no correlation between breast ultrasound and clinical examination, which means that breast enlargement resulting from obesity does not necessarily mean true thelarche.

Calcaterra et al. in 2009 examined the use of breast ultrasound for precocious puberty diagnosis in 60 precocious pubertal girls. They showed that the breast size more than $0.85 \mathrm{~cm}$ is associated with rapid progression of puberty and uterus size more than $5 \mathrm{~cm}$, LH peak more than 7, endometrial echo in pelvic ultrasound, oestradiol level more than 50, and bone age more than 2 standard deviations above chronological age are related to more rapid progression of puberty [17]. In our study, only 3 children had uterine volume more than $5 \mathrm{~cm}^{3}$. Two of them were treated with a diagnosis of rapidly progressive precocious puberty and another one did not come and did not cooperate with bone age determination.

Youn et al. in 2015 evaluated 68 girls under age 8 years; 11 of them had no symptoms of puberty, 32 had premature thelarche symptoms, and 26 had precocious puberty symptoms. Breasts were evaluated by ultrasound. Laboratory tests including $\mathrm{LH}, \mathrm{FSH}$, and oestradiol were done and chronologi- cal and bone age were determined and compared with ultrasonic findings. In this study it was shown that breast ultrasound can help diagnose true thelarche. However, its use for differentiation between true precocious puberty and premature thelarche is limited, and hormonal tests should be considered for better differentiation [15]. In our study, it was shown that ultrasound can diagnose thelarche in obese and overweight children before clinical examination and Tanner scale; therefore, it helps in earlier and faster diagnosis of precocious puberty. Also In our study, obesity grading had no significant relation with Tanner staging of puberty bilaterally, but it had significant and inverse correlation with ultrasonic staging of the right breast. Although it has and inverse relationship in the left breast, it was not significant. On the other hand, high grade of obesity did not cause higher staging of clinical examination. Younger children had higher BMI.SDS, but there was no correlation between BMI.SDS and uterine and right ovarian volume.

Zhou et al. in 2015 examined the effect of obesity in LH peak by Gonadotropin-releasing hormone $(\mathrm{GnRH})$ stimulation test in precocious pubertal girls. In this study, 60 children were divided into 3 groups: normal weight (20 children), overweight ( 20 children), and obese ( 20 children). All the children had similar chronological age, but the bone age of obese and overweight children was more than that of normal children. BMI level had a negative relationship with LH peak level (by $\mathrm{GnRH}$ stimulation test and sex hormone binding globulin [SHBG]) but a positive relationship with neurokinin and leptin levels. In ultrasonic examination of the pelvic organs, the relationship between uterine volume, width, ovarian volume, and breast ultrasound grade was significant [18].

In our study, the laboratory examination $\mathrm{LH}$ average was 0.57 , FSH average was 1.93, and oestradiol average was 20.09. LH and oestradiol have no significant relationship with $\mathrm{BMI}$, variables of the right breast, left breast, uterus, and ovary. FSH level had correlation with $\mathrm{LH}$ level, uterine volume, and right/left breast bud diameter but had no significant relationship with BMI, other variables of the right/left breast, and ovarian volume. In our study a $\mathrm{GnRH}$ stimulation test was not done because it is not specific and was unnecessary.

In the review study of Giabicani et al. in 2013 it was shown that $\mathrm{LH}$ basic concentration and $\mathrm{LH}$ peak concentration after $\mathrm{GnRH}$ stimulation test and $\mathrm{LH} / \mathrm{FSH}$ ratio has no conformity with progress of clinical criteria of puberty [19]. Also in our study, there was a correlation between FSH level and right/left breast bud diameter and uterine volume, but there was no significant relation between laboratory findings and precocious puberty and thelarche variables.

\section{Conclusions}

We conclude that ultrasound can diagnose true thelarche in obese or overweight children before clinical diagnoses using the Tanner scale. It is also a non-aggressive and acceptable method by families that can be used for an earlier, easier, and more accurate diagnosis of thelarche and precocious puberty. 


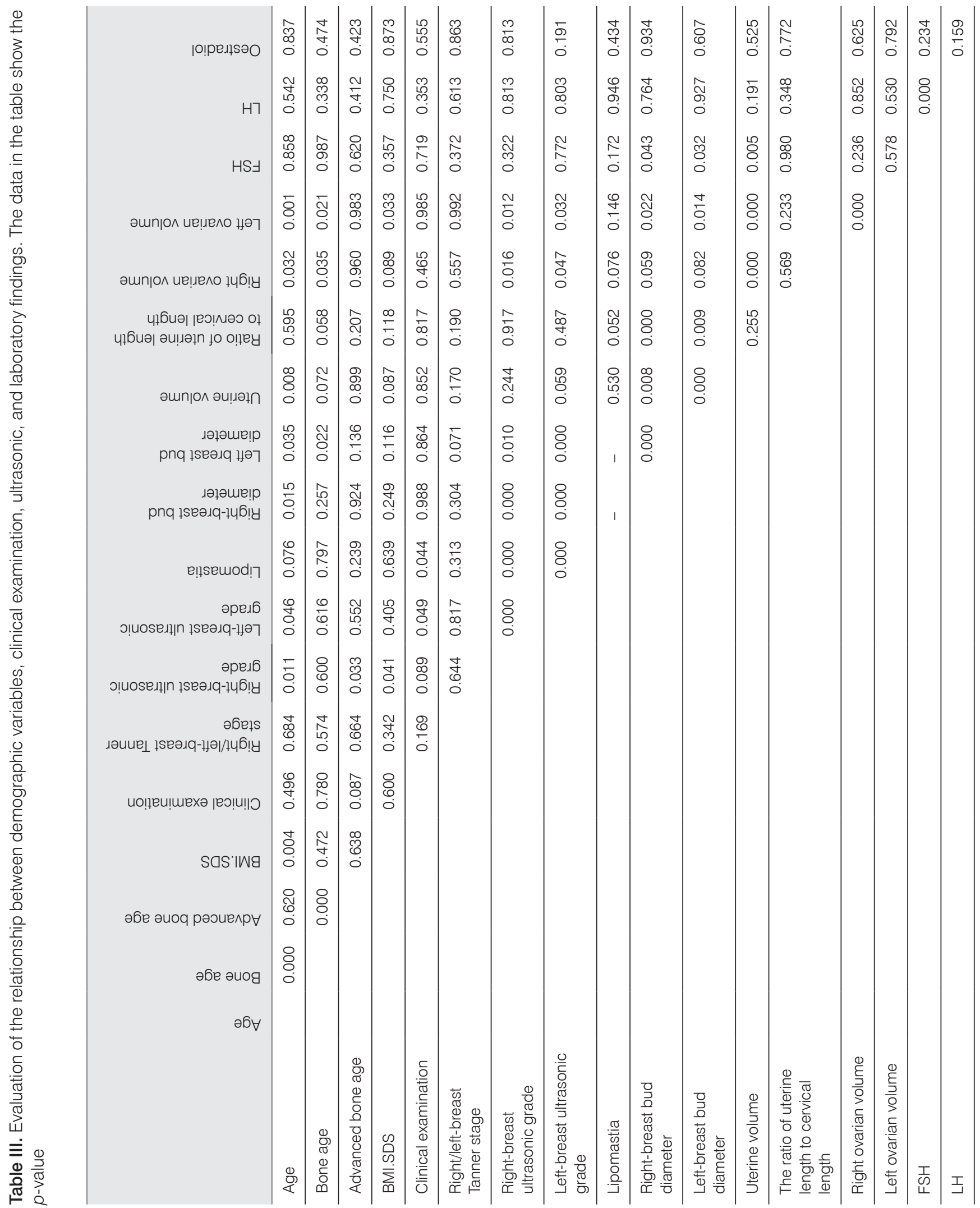




\section{References}

1. Kumar M, Mukhopadhyay S, Dutta D. Challenges and controversies in diagnosis and management of gonadotropin dependent precocious puberty: an Indian perspective. Indian J Endocrinol Metab 2015; 19: 228-235. doi: 10.4103/2230-8210.149316.

2. Fuqua JS. Treatment and outcomes of precocious puberty: an update. J Clin Endocrinol Metab 2013; 98: 2198-2207. doi: 10.1210/ jc.2013-1024.

3. Kim D, Cho S-Y, Maeng S-H, et al. Diagnosis and constitutional and laboratory features of Korean girls referred for precocious puberty. Korean J Pediatr 2012; 55: 481-486. doi: 10.3345/kjp.2012. 55.12.481.

4. Kim EY, Lee MI. Psychosocial aspects in girls with idiopathic precocious puberty. Psychiatry Investig 2012; 9: 25-28. doi: 10.4306/ pi.2012.9.1.25.

5. Sultan C, Gaspari L, Kalfa N, Paris F. Clinical expression of precocious puberty in girls. Pediatric and Adolescent Gynecology. 22 Karger Publishers 2012; 84-100.

6. Neely EK, Crossen SS. Precocious puberty. Curr Opin Obstet Gynecol 2014; 26: 332-338. doi: 10.1097/GCO.0000000000000099.

7. García CJ, Espinoza A, Dinamarca V, et al. Breast US in children and adolescents. Radiographics 2000; 20: 1605-1612. doi: 10.1148/ radiographics.20.6.g00nv171605.

8. de Vries L, Guz-Mark A, Lazar L, et al. Premature thelarche: age at presentation affects clinical course but not clinical characteristics or risk to progress to precocious puberty. J Pediatr 2010; 156 : 466-471. doi: 10.1016/j.jpeds.2009.09.071.

9. Kaplowitz PB, Slora EJ, Wasserman RC, et al. Earlier onset of puberty in girls: relation to increased body mass index and race. Pediatrics 2001; 108: 347-353. doi: 10.1542/peds.108.2.347.

10. Bueno ML, Sarría AC, Bueno MS. Bone maturation in obese Aragonese children of both sexes. An Esp Pediatr 1996; 45: 29-32.

11. Anderson SE, Dallal GE, Must A. Relative weight and race influence average age at menarche: results from two nationally representative surveys of US girls studied 25 years apart. Pediatrics 2003; 111 (4 Pt 1): 844-850. doi: 10.1542/peds.111.4.844.

12. Chonchaiya W, Wacharasindhu S, Trinavarat $P$, Mahayosnond A. Is the severity of obesity associated with poor prediction of adult height and height gain? Asian Biomed 2010; 2: 471-476.

13. Nagasaki K, Kikuchi T, Hiura M, Uchiyama M. Obese Japanese children have low bone mineral density after puberty. J Bone Miner Metab 2004; 22: 376-381. doi: 10.1007/s00774-004-0498-y.

14. Ellis K, Shypailo R, Wong W, Abrams S. Bone mineral mass in overweight and obese children: diminished or enhanced? Acta Diabetol 2003; 40 Suppl 1: S274-S277. doi: 10.1007/s00592-003-0085-Z.

15. Youn I, Park SH, Lim IS, Kim SJ. Ultrasound assessment of breast development: distinction between premature thelarche and precocious puberty. AJR Am J Roentgenol 2015; 204: 620-624. doi: 10.2214/AJR.14.12565.

16. Proos LA, Lönnerholm T, Jonsson B, Tuvemo T. Can the TW3 Bone Age Determination Method Provide Additional Criteria for Growth Hormone Treatment in Adopted Girls with Early Puberty? Horm Res Paediatr 2010; 73: 35-40. doi: 10.1159/000271914.

17. Calcaterra V, Sampaolo P, Klersy C, et al. Utility of breast ultrasonography in the diagnostic work up of precocious puberty and proposal of a prognostic index for identifying girls with rapidly progressive central precocious puberty. Ultrasound Obstet Gynecol 2009; 33: 85-91. doi: 10.1002/uog.6271.

18. Zhou X-L, Fu J-F, Jin J-H, et al. Effects of obesity on peak level of luteinizing hormone in gonadotropin-releasing hormone agonist test and obesity-related hormones in girls with central precocious puberty. Zhongguo Dang Dai Er Ke Za Zhi 2015; 17: 763-768.

19. Giabicani E, Allali S, Durand A, et al. Presentation of 493 consecutive girls with idiopathic central precocious puberty: a singlecenter study. PloS One 2013; 8 (7): e70931.doi: 10.1371/journal. pone.0070931. 